Article

\title{
Reducing Recurrent Care Proceedings: Building a Local Evidence Base in England
}

\author{
Pamela Cox ${ }^{1, *}$, Susan McPherson ${ }^{2}$ (D) Claire Mason ${ }^{3}$, Mary Ryan ${ }^{4}$ and Vanessa Baxter ${ }^{2}$ \\ 1 Department of Sociology, University of Essex, Colchester CO4 3SQ, UK \\ 2 School of Health and Social Care, University of Essex, Colchester CO4 3SQ, UK; smcpher@essex.ac.uk (S.M.); \\ vanessa.baxter@essex.ac.uk (V.B.) \\ 3 Department of Sociology, Lancaster University, Lancaster LA1 4YT, UK; c.mason@lancaster.ac.uk \\ 4 Ryan Tunnard Brown Consultants, London N19 4PR, UK; maryryan@ryantunnardbrown.com \\ * Correspondence: pamcox@essex.ac.uk
}

Received: 30 September 2020; Accepted: 5 November 2020; Published: 18 November 2020

check for updates

\begin{abstract}
Recent studies of public law care proceedings within the family justice system in England and Wales suggest that up to a quarter of all mothers who appear in such proceedings will reappear within a subsequent—or recurrent—-set of such proceedings within seven years. In the last decade, new interdisciplinary research spanning social work, clinical psychology and sociology has defined and investigated the previously hidden challenge and social costs of 'recurrent care proceedings' (RCP). This article adds to this new field by analysing the core values, practice and impact of three different local services in the northwest of England working with birth parents to reduce the risk of recurrent proceedings. The article combines data gathered from the three distinct services using a common evaluation framework co-produced by the authors working with service leads, practitioners and users. It explores how all three services are seeking to reduce the risk of recurrent care proceedings in their local areas without requiring women to use long acting reversible contraception (LARC) or other forms of contraception as a condition of accessing the service. It concludes that insights gained from these and cognate services can inform an emergent community of practice in the recurrent care field.
\end{abstract}

Keywords: recurrent care proceedings; family justice; service evaluation; child removal; birth parents

\section{Introduction}

One in four birth mothers who have a child taken into care in England are likely to re-appear in care proceedings within seven years [1]. Women in this situation have typically experienced structural disadvantage in multiple domains including socio-economic deprivation, histories of trauma and abuse, low educational attainment and lack of access to healthcare [2,3]. For decades, their needs-along with the wider issue of 'recurrent care proceedings' (RCP) — went unacknowledged in policy frameworks. Although known to a range of local services prior to the removal of their child, these mothers typically fell through the cracks between children's social care and adult mental health and treatment services thereafter, only re-appearing on practitioners' radar when they became pregnant again.

From the early 2010s on, in response to increasing recognition of recurrence by practitioners and alongside a programme of research to systematically document the scale of recurrence and highlight the associated ethical and policy challenges [1,3-5], a number of new services were established in England seeking to reduce recurrent care proceedings at the local level. Arising in different contexts in different places, they were typically shaped by local authority concerns to stem the number of 'revolving door' parents in their own areas. They were, and remain, distinct in that they have been funded and commissioned in different ways, with some nested in local authorities and others in voluntary sector 
organisations, including women's centres and family support bodies. They nevertheless share many features in common, offering flexible modes of engagement typically shaped through the iterative interactions of frontline keyworkers and service users. One service, Pause, received substantial funding from the Department for Education (DfE); there are now 33 'Pause practices' across England and Northern Ireland. In addition to Pause, at least 20 further locally developed services and programmes, including the three examined here, have also been established in England and Wales.

Service development in this field has been rapid and significant. Between them, these new services engage with hundreds of families each year. Published peer reviewed studies of service effectiveness in this field remain relatively rare, however, with only two available to date [6,7]. This article offers the first combined analysis of independent evaluations of three of these new RCP services in the UK. We present new data on the design, delivery and effectiveness of the services and discuss the value, and development, of co-produced methods of collecting that data. The article seeks to extend the local evidence base around 'what works' as a step towards creating communities of good practice [8-10] via solution-focused peer-to-peer learning to reduce recurrent care proceedings in England. It also highlights issues relating to the different forms of evidence and outcomes valued in the field by different stakeholders, arguing that 'what works' in this field must be informed by 'what matters' to parents as well as to service commissioners and auditors.

The three local RCP services discussed in this article were all developed from the ground-up, funded from different sources. They are distinct from each other in many ways. However, they are underpinned by a set of common core values, follow similar service designs and have similar theories of change. There is a key difference between them and the national service model that Pause initially developed in Hackney and scaled up from 2015 onwards through DfE funding [11]. While Pause typically requires women to agree to use a form of long-acting reversible contraception (LARC) or other form of birth control as a condition of engagement, these three services (along with the majority of other non-Pause services) do not. They do all encourage women to seek advice on their reproductive health and to take up a form of contraception (including LARC), but they do not require this. Indeed, all three services have evolved over time to engage in some way with women who are, or who become, pregnant. This is a significant point because it means that, de facto, the effectiveness of these services in reducing recurrent care proceedings does not rely on the uptake of LARC or other forms of contraception to avoid pregnancy. It means that they work from the premise that some of their service users may be actively considering the prospect of having more children, requiring services to support them to develop parenting capacities that may help avoid care proceedings.

In this article, we present combined evaluation outcomes from the three local services, focusing on outcomes relating to parent social situations, avoidance of care proceedings, psychological wellbeing measures and parent experiences of the service. We seek to explore the dynamics of service models that seek to reduce RCP but that do not make service delivery formally contingent or conditional upon service users' uptake of contraception.

\section{Materials and Methods}

\subsection{Mixed Methods Evaluation}

We seek to apply the principles of mixed methods evaluation as summarised by Burch and Heinrich [12], notably the principle that the selected methods should be integrated across the whole cycle of the research process, from planning and data collection to analysis, dissemination and re-design. Our commitment to mixed methods is linked to our experiences as an interdisciplinary team spanning clinical psychology and sociology as well as a range of practitioner roles in law, social work and safeguarding. It is also connected to our interest in realist evaluation practice [13]. Realist evaluators argue that it is not interventions in and of themselves which 'work' but the reasoning and opportunities of the people delivering and experiencing interventions which makes them work. Our different modes of data collection-outlined below-were designed to capture the varied dynamics of service 
design, delivery and experience. We amended our data collection tools to reflect changes in service design and delivery as these occurred, most notably to capture outcomes for those service users who became pregnant or had children previously removed returned to them in the course of their service engagement. In this way, and in line with realist approaches, we were able to document the impacts of service innovation as these unfolded.

\subsection{Service Models and Context}

To protect service user and staff confidentiality, the services evaluated are presented anonymously throughout this report. All three services are based within densely populated, high deprivation, urban areas in the northwest of England; were established between 2014 and 2017; and accept referrals of women (or couples) who have had at least one child removed previously and are, therefore, deemed to be at risk of a 'repeat removal'. Two of the services (A and C) accept women who are pregnant at the point of referral alongside those who were not, and one service (B) only accepts women who are not pregnant at the point of referral but continues to work with them if they become pregnant thereafter. The three services are distinct from each other, with different funding and governance structures including charitable, local authority funding and NHS structures and/or funding. Nevertheless, they have much in common. Referral routes are broadly similar, with most service users being referred via local adult or children's social care agencies, with some self-referring. Each service has a service lead or manager along with a very small number (ranging between 2-7) of dedicated but sometimes fractional staff drawn from the following pools: key workers, family support workers, social workers, counsellors, specialist health workers or midwives. None employ clinically-trained therapists or psychologists.

All three services give advice on contraception as part of the support offered and this can include immediate access to support and information about a range of contraceptive and sexual health choices as well as information on birth spacing and how an 'early' pregnancy during engagement might limit a woman's ability to care for a further child safely.

The services use a variety of approaches to working with parents but all primarily offer person-centred support focusing on the needs of the individual and working with them in the context of their existing relationships and social situations. Service A, for example, aims to incorporate systemic approaches in their work by integrating current positive family and friends' relationships into the plan to benefit from the support and understanding of a wider network. Similarly, Service B aims to establish a relationship with individual parents to build trust and give support to help them meet their own personal health and social needs while Service C employs an 'assertive outreach' approach, often working outside of 'normal' hours, being flexible and creative in their approaches and meeting venues. Services offer some parents counselling alongside social care key working. They also offer a similar range of support options which include support sessions on parenting, health, wellbeing, financial resilience, home management, homelessness prevention and housing. All three services have developed ways of responding to women who are either pregnant at referral or become pregnant during engagement with their service. Services $B$ and $C$ have formalised this response by offering different pathways for parents requiring 'post-proceedings', 'pre-birth' or 'post-birth' support.

This distinction between service models was either built into the initial service design or evolved over time as services widened their remit in response to the needs of their users. Work with pregnant or post-birth mothers who retained their new child would then extend to more focused support on parenting skills and helping parents to learn how to provide a safe and loving environment for their baby. The ways in which pregnancy and birth was incorporated into service models also impacted on the duration of intervention and the degree to which the service integrated with other agencies. 
The length of support offered varies by service specification and the degree of engagement by parents but tends to be in the region of up to 12 months intensive support plus some additional less intensive support up to school age for those services offering post-birth support and where children remain with a parent. Service A works intensively alongside each woman over the period of a year through focussed one to one support for two hours per week, although the timescale is flexible and centred around individual need. If a woman becomes pregnant, she can re-enter the project for a further 6-9 months to be supported with the social care assessment process. Service B currently has no maximum limit of time when a woman can be supported, but has a 'moving on' pathway which includes links to other support services. Women are moved into this at the point when they and their keyworker feel they are ready for a more light touch approach than the initial intensive support. Our evaluation of Service B did not include women on the 'moving on' pathway. In Service C, post-proceedings support is normally available for a maximum of two years but for a maximum of five years in certain circumstances. If a woman who was pregnant at the start of their involvement is able to keep their baby then family support is provided by Service $C$ until the child starts primary school. Over a maximum of five years, the support parents receive reduces until eventually parents exit the service when their child begins school.

All three services have a physical centre where some counselling or other specific support services would be provided; but key working was largely framed around home visits, co-working with other services at other locations. Key workers liaise with local sexual health, mental health, drug and alcohol and domestic abuse services as well as social workers, early years' providers and healthcare professionals depending on the needs of the parent and whether they are post-proceedings, pre-birth or post-birth.

\subsection{Evaluation Design}

Evaluation is a key element of service planning, development and delivery both in social care and health sectors. It allows service users to give feedback on their experiences and managers and practitioners to understand how and why provision is (or is not) working to mitigate a particular local challenge or meet a particular local need. Whilst there are some commonly espoused techniques and tools for evaluation in health and social care, recurrent care services require careful adaptation of these processes to fit the context and nature of the client group and to enable a common approach across different localised services. Our evaluation methodology was informed by our clinical and theoretical research in trauma-informed, attachment and relationship-based approaches to support new and emerging recurrent care services in developing their intervention models $[5,6]$. As outlined above, it was also informed by realist evaluation models that embrace the complexity of real-time responsive service evolution [14]. Ethical approval was provided by the University of Essex, Faculty of Social Science Ethics Committee.

The evaluation approach employed for the services included in this study was co-produced by a multi-disciplinary team of academics in partnership with local service providers. The framework was developed iteratively over the course of working with different local providers across the UK, through collaboration with experts in the field. It was critical to co-produce an evaluation methodology in order to ensure that the data collection procedures were practical and easy to use for both key workers and parents given the nature of key working in this field which involves visiting client homes, working to gain trust and build up an engagement with each parent while responding flexibly to their often complex lifestyles and lack of trust in professionals. The evaluation tools had to integrate with the main provider's (NHS, local authority or charity) routine case monitoring systems in a way which complemented rather than duplicated key worker case management tasks. The methodology also needed to enable the independent evaluation team working geographically separately from providers to access and analyse data remotely while complying with different organisations' information governance policies. 
The 'evaluation toolkit' developed through this approach is available as an open access resource via https:/www.researchinpractice.org.uk/media/3967/s2-evalutaion-user-guide.pdf and has three components. The first is a 'case tracker' which can be used either as an Excel spreadsheet or as an online survey format completed by key workers using any digital device (iPad, computer or mobile phone). The tracker collects a range of information about each parent referred to the service. It requires data to be entered by the practitioner at initial referral, at initial engagement, and at 6 months and 12 months follow-up (plus longer if required). The follow-up periods for Services A and B were 6 and 12 months while the follow-up period for Service $C$ was 5 years. The information collected includes basic but often sensitive details about the parent's past and current situation including housing, relationships, mental health and alcohol use. The tracker also collects data about contraception use, pregnancy and child safeguarding decisions and outcomes. Information is recorded by key workers and is gathered from various sources including referral processes, conversations between parent and practitioner and key worker liaison with other services.

The second component is a set of validated measures completed by parents (although practitioners are usually present to assist if necessary) at initial engagement and then at six month intervals. Although services were not formally linked with NHS mental health services, nor explicitly established to treat mental health conditions, the evaluation set out to establish the degree of psychological disturbance among parents and to find out what impact if any the services had on recording or ameliorating these difficulties. This was critical particularly given the high levels of social disadvantage documented above along with high rates of past and current trauma $[15,16]$.

Validated measures were used in Service A and B only. This is because Service C was based on retrospectively collected data only, relying on case records and key worker memory, whereas psychometric measures can only be collected prospectively, based on the current feelings of the person completing them. Measures were completed by the parent online using a digital device (iPad, computer or mobile phone) accessed via a secure web link. The measures were selected based on consultation with experts, frontline workers and psychological therapy researchers with a view to identifying measures which had good psychometric properties, appropriate levels of comprehensibility, relevance to the client group and reflected the key domains of wellbeing which were considered to impact on these parents. Measures used were the Rosenberg self-esteem scale [17]; the Adult Attitude to Grief scale [18]; the CORE [19] to measure overall psychological wellbeing; the PTSD Checklist (PCL) civilian version to measure trauma symptoms [20]; and the Quality of Life Enjoyment and Satisfaction Questionnaire (QLESQ) short form [21] to measure quality of life. Given that each recurrent care service was working with a small number of parents in a naturalistic and individualised manner, the use of these measures was not intended as a means of conducting group level statistically powered pre-post comparisons. The purpose was to provide an indication of individual levels of psychological need and clinically significant change using statistical approaches to examine individual level change [22].

The third component was parent interviews (Service A and C only, owing to resources available) which were carried out with a sub-sample of mothers $(n=13)$ in order to gain more in-depth understanding about their experiences and perspectives. Prospective participants (for both services) were identified by the service staff and all interviews arranged with their assistance. The topic guides covered the background to the referral, expectations for the service and goals for personal change, experiences of the service and how they felt they progressed (or not) with their goals, relationships with their child(ren), confidence as a parent and views about the future. Interviews were recorded, transcribed and thematic analysis [23] used to group concepts and themes that emerged from the data. For the purposes of this article, we have combined selected interview data from both services. 


\section{Results}

Table 1 below shows the total number of women tracked for evaluation purposes across the three services and the number of women for whom data was available for each aspect of the evaluation.

Of the 182 women tracked, $17 \%$ were aged 19 or under, $53 \%$ were between $20-29$ years, $28 \%$ between 30-39 years and 3\% aged over 40 years. The majority ( $84 \%$ ) were described by key workers as white, $15 \%$ as 'Other' and 1\% as black' or 'black Caribbean'.

Table 1. Numbers of women tracked in each service evaluation.

\begin{tabular}{|c|c|c|c|c|}
\hline Data Collected & Service A & Service B & Service C & Total \\
\hline Changes in personal, social and economic situations (Case Tracker) & 50 & 22 & 37 & 109 \\
\hline Births and removals (Case Tracker) & 50 & 22 & $110 *$ & 182 \\
\hline Psychological wellbeing (Validated Measures) & 21 & 7 & 0 & 28 \\
\hline Experiences of the service (Qualitative Interviews) & 5 & 0 & 8 & 13 \\
\hline Total number of mothers tracked & 50 & 22 & 131 & 182 \\
\hline
\end{tabular}

* For Service C, full Case Tracker data was collected on the 37 women who had engaged with the service during the evaluation period plus partial data relating only to births and removals of children for an additional 73 women.

\subsection{Changes in Personal, Social and Economic Situations}

Here, we report data collected in the Case Tracker part of the toolkit. Figures (percentages) at referral are combined for all three services; whereas follow up figures are combined for Service A and B (because the follow-up period is the 12 months for both) and reported separately for Service C (because the follow-up period is 5 years). Percentages are based on all the 109 women for whom we had data on changes in personal, social and economic situations (see Table 1). Between them, they had experienced the prior removal of over 200 children. Where information was available on partners, all partners were male, and in some cases they were birth fathers to the children who had been removed, or (prospective) birth fathers to those (due to be) born during the course of engagement.

The evaluations aimed initially to establish the social, economic and psychological conditions that mothers, as core service users, were facing in their lives. While $74 \%$ of all mothers had stable accommodation at referral, $16 \%$ were homeless, had rent arrears or were at risk of eviction. After engagement with the services for at least 12 months, the proportion in stable accommodation had increased to $89 \%$ (A and B) and to $94 \%$ after 5 years (Service C). The majority (86\%) of mothers were not working or unable to work at referral; this proportion decreased slightly for Service A and B but increased slightly for Service C, which may be due to the large number of Service C mothers who had and kept babies. Just over half of women (53\%) at referral were on medication for mental health problems. This proportion increased over time for all of the services. While $11 \%$ of mothers were involved with probation services at referral, none were at the final follow up point for each service. While $67 \%$ of mothers reported partner abuse within the previous year at referral, this number fell to around a third at the final follow up points for each service. At referral, $27 \%$ of the mothers revealed problems with alcohol and $22 \%$ revealed problems with drug use, but these proportions both decreased by the follow up points to $14 \%$ and $17 \%$, respectively. Twenty three percent of the women in all three services were care leavers, while another $30 \%$ had had previous involvement with Social Care as children. This reflects a set of difficult and complex situations for mothers at referral reflecting multiple disadvantages and needs for social and clinical support.

\subsection{Births and Removals of Children}

These findings are based on full or partial Case Tracker data available from 182 women in total (see Table 1). As outlined above, all of the women tracked in these evaluations (or their partner, in rare cases) had experienced the removal of one or more of their children. All three services aimed to reduce the likelihood of further or 'repeat' removals of infants subsequently born to these women without requiring them to take up LARC or other forms of contraception as condition of engagement. All three, however, sought to encourage and help women to access sexual health and contraceptive services. 
The proportion of women using contraception at referral in Service A and B was 33\%. The proportion using contraception at six months was $68 \%$ indicating that both services succeeded in encouraging more mothers to use contraception but did not lead to all mothers using contraception which was not their primary aim. All of the mothers being tracked in Service C were pregnant at referral because of the difference in service model and referral criteria and so contraception use was not relevant at the point of referral. However, staff were clear that for parents who later retained care of their children following birth, contraception was always encouraged and actively pursued if necessary.

Although these services did not seek to prevent all pregnancies and were prepared to work with women pregnant at referral or who became pregnant during engagement, they were still able to demonstrate that they could help to avoid removals. Without intervention, it can be suggested that any child born to one of these women would have been at some risk of removal, either through care proceedings resulting in special guardianship orders or adoptions, or removed at birth with the possibility of reunification depending on the outcome of proceedings. Table 2 indicates that of 127 babies born to mothers during the evaluation period, 31 babies became looked after children (LAC) or adopted during the evaluation period while 96 remained with their mother or other family member (including special guardianship orders). Twelve children removed from their mothers' care prior to engagement with a service were returned to their care during the course of engagement.

Table 2. Births and removals of children.

\begin{tabular}{|c|c|c|c|c|}
\hline & A & B & $\mathrm{C}$ & Total \\
\hline Time period evaluated & 12 months & 12 months & 5 years & \\
\hline Mothers tracked in evaluation & 50 & 22 & 110 & 182 \\
\hline Births during evaluation period & 0 & 1 & 126 & 127 \\
\hline Children born and became LAC/adopted & 0 & 1 & 30 & 31 \\
\hline Children born and remained with mother or family & 0 & 0 & 96 & 96 \\
\hline Children previously removed but now returned to parent & 10 & 2 & - & 12 \\
\hline
\end{tabular}

\subsection{Psychological Wellbeing}

Measures of psychological wellbeing were collected for a small sub-sample within two services (A and B). Table 3 below shows scores for each area of wellbeing. The table columns show the mean score found in published studies of clinical samples alongside the mean score at engagement for each service. The table then shows the percentages of mothers from the two services combined who were within the clinical range at engagement. The final four columns show the percentages of mothers who at six months had not changed, had deteriorated, had improved (but stayed in the clinical range) or had improved enough to move out of the clinical range.

The mean scores on all measures indicate that mothers in these services have similar levels of need to adults receiving formal mental health care. This suggests that there is a significant unmet need among this group of women for psychological care. In many domains, more than half the mothers fall within the clinical range of scores and for grief, trauma and quality of life a large proportion of mothers fall in the clinical range. Although the services are not providing specialist therapeutic input, it is notable that a modest proportion of mothers improve significantly over 6 months, although most do not change and some deteriorate. 
Table 3. Psychological wellbeing.

\begin{tabular}{|c|c|c|c|c|c|c|c|c|c|}
\hline & \multirow[b]{2}{*}{ Clinical Comparison Sample } & \multirow[b]{2}{*}{ Clinical Mean } & \multicolumn{3}{|c|}{ At Engagement } & \multicolumn{4}{|c|}{ At 6 Months } \\
\hline & & & $\begin{array}{c}\text { Service A } \\
\text { Mean (SD) }\end{array}$ & $\begin{array}{l}\text { Service B } \\
\text { Mean (SD) }\end{array}$ & $\begin{array}{c}\% \text { in } \\
\text { Clinical Range }\end{array}$ & $\begin{array}{c}\% \\
\text { No Change }\end{array}$ & $\begin{array}{c}\% \\
\text { Deteriorate }\end{array}$ & $\begin{array}{c}\% \\
\text { Improve } \\
\end{array}$ & $\begin{array}{l}\text { \% Moved out } \\
\text { Clinical Range }\end{array}$ \\
\hline Self-esteem * & $\begin{array}{l}\text { Women with PTSD from } \\
\text { intimate partner violence [24] }\end{array}$ & 14.0 & $\begin{array}{l}14.8 \\
(1.9)\end{array}$ & $\begin{array}{l}14.1 \\
(1.9)\end{array}$ & 50 & 71 & 7 & 7 & 14 \\
\hline Grief (poor resilience) & \multirow{3}{*}{$\begin{array}{l}\text { People attending a bereavement } \\
\text { service [18] }\end{array}$} & 5.3 & $\begin{array}{l}6.1 \\
(2.3) \\
\end{array}$ & $\begin{array}{l}4.9 \\
(4.2)\end{array}$ & 50 & 71 & 14 & 14 & 0 \\
\hline $\begin{array}{c}\text { Grief } \\
\text { (over-controlled/denial) }\end{array}$ & & 8.0 & $\begin{array}{l}8.7 \\
(1.9) \\
\end{array}$ & $\begin{array}{c}8.9 \\
(3.7)\end{array}$ & 57 & 79 & 14 & 0 & 7 \\
\hline Grief (overwhelmed) & & 8.9 & $\begin{array}{l}10.6 \\
(1.9)\end{array}$ & $\begin{array}{l}9.4 \\
(2.2) \\
\end{array}$ & 71 & 64 & 14 & 14 & 7 \\
\hline $\begin{array}{l}\text { Psychological distress } \\
\text { (overall) }\end{array}$ & \multirow{5}{*}{$\begin{array}{l}\text { Women receiving NHS } \\
\text { psychology services [19] }\end{array}$} & 1.85 & $\begin{array}{c}1.8 \\
(0.7)\end{array}$ & $\begin{array}{c}1.9 \\
(0.5)\end{array}$ & 43 & 43 & 21 & 21 & 14 \\
\hline Psychological functioning & & 1.84 & $\begin{array}{l}1.8 \\
(0.6)\end{array}$ & $\begin{array}{l}1.9 \\
(0.4)\end{array}$ & 29 & 50 & 36 & 7 & 7 \\
\hline Psychological wellbeing & & 2.41 & $\begin{array}{c}1.9 \\
(0.7) \\
\end{array}$ & $\begin{array}{c}2.1 \\
(0.9) \\
\end{array}$ & 21 & 79 & 7 & 0 & 14 \\
\hline Psychological problems & & 2.28 & $\begin{array}{l}2.3 \\
(1.0)\end{array}$ & $\begin{array}{l}2.6 \\
(0.8)\end{array}$ & 50 & 36 & 14 & 14 & 36 \\
\hline Psychological risk & & 0.61 & $\begin{array}{c}0.8 \\
(0.9)\end{array}$ & $\begin{array}{c}0.6 \\
(0.9) \\
\end{array}$ & 36 & 64 & 14 & 0 & 21 \\
\hline Trauma & $\begin{array}{l}\text { Women with partner } \\
\text { violence [25] }\end{array}$ & 62.3 & $\begin{array}{l}55.2 \\
(17.5)\end{array}$ & $\begin{array}{l}63.4 \\
(7.8)\end{array}$ & 36 & 29 & 21 & 21 & 29 \\
\hline Quality of life * & People with PTSD [26] & 55.7 & $\begin{array}{l}39.8 \\
(10.5)\end{array}$ & $\begin{array}{l}38.3 \\
(9.9)\end{array}$ & 93 & 79 & 14 & 0 & 7 \\
\hline Number of mothers & - & - & 21 & 7 & 14 & 14 & 14 & 14 & 14 \\
\hline
\end{tabular}




\subsection{Experiences of the Service}

Three main themes emerged from qualitative interviews with 13 mothers. These emerged both from the temporal structure of the interviews which sought to address elements of the women's past and present experiences and their views of their likely future, and from the women's readiness to engage with that structure. The first theme concerns the ways in which service key workers developed trust with mothers in a way which appeared to acknowledge the past trauma that they had typically experienced. The second theme is concerned with the way in which mothers felt the service helped them develop social skills and confidence; the third theme concerns the ways in which mothers appeared to be able to look forward and hope for a better future as a result of engaging with the service. In designing our initial evaluation tools, we had not expected that a significant number of service users would be, or would become pregnant, or have children previously removed returned to them. We subsequently revised our tools to better capture their experience. Our interviews also allowed some mothers the chance to address this in their own words. Eight of them had been supported either to keep newborns during the evaluation period, or to resume the care of children previously removed. They offer particular insight into the styles of service delivery that can assist those who have had children removed in the past to be supported to parent safely in the future.

\subsubsection{Developing Trust in the Context of Past Trauma}

Mothers tended to trace their difficulties back to their own childhoods which often involved some form of childhood abuse or maltreatment. Women described how these experiences continued to impact on their lives as adults. They also talked about more recent abusive relationships and recognising a link with their children having being removed.

I've been doing some work with $X$ on healthy and safe relationships. I find it very helpful. I was abused and it kind of affected the way I looked at men. Like I don't know when, when you grow up without a father figure, and then you get abused and... it's like you're craving that father figure in somebody else. So, whoever shows you a bit of attention, you just fall for it. ... I am not like that anymore. I don't think about it. If I am thinking about myself, I'll always question whether it's right for $D$ [child]. (Mother Service C)

Traumatic experiences were often mirrored in women's experiences of having children removed. For one mother in Service A the removal of her children had come as a 'shock out of the blue', a catastrophic incident that completely shattered what she had considered to be a very ordinary and stable life. Moreover, most women felt that they had not received any support or help to deal with the issues that were impacting on them and their ability to parent.

I didn't get any help, I was isolated and I was in a domestic violence relationship. My mental health just got really bad and I couldn't cope with the child... I didn't get offered no help [from Children's Services] the whole thing was about my mental health and me not coping ... (Mother, Service A)

Given women's past difficulties with relationships including past abuse, recent abuse and the mistrust of children's social care services resulting from re-traumatisation at removal of their children, developing a relationship with key workers was both difficult and critical. Women described the importance of the regularity of contact and the utility of support offered such as a regular chat over coffee, getting advice, support with practical tasks and linking to other support services and programmes.

My one to one time is really important, I really like that it is always [keyworker name] seeing me. I have had the same worker since the beginning ... She has really helped me to see patterns in my life and helped me to see my triggers and to cope with them better. (Mother, Service A)

She come out like a couple of days a week, but if I needed anything, I could just ring her. And she'd be there like a shot, she'd just come straight away. (Mother, Service C) 
Women appeared to develop trust in key workers partly as a result of the direct support with their ongoing interactions with children's services, courts or other agencies such as housing services. These other agencies had previously been experienced as punitive or difficult to trust and key workers helped mothers navigate these difficult interactions.

[Keyworker] comes to the Child in Need meetings, and helps explain everything, I find it difficult to explain things so it helps with her being there. (Mother, Service A)

[Keyworker] is ... when she wants something done, you get it done ... she is not stopping until it's done. Which is a good thing. Because that's what kind of person I need. (Mother, Service C)

They've been helping me with trying to find somewhere better to live than shared accommodation. They've been helping with my benefits if I'm struggling, even if I'm having a bad day I can just ring them up and speak to them over the phone. They even take me out for a drink or something to eat. (Mother, Service C)

This kind of key worker support was held up in contrast to interviewees' prior interactions with children's services which had prioritised children's needs.

Social workers are obviously there to protect the baby, but also see issues and find out facts and they're not really... they've got so many cases to deal with, they're not really there for you if you need them, they're there for the child if the child's in danger or in trouble. Whereas, the [Service C] are there for you, so if you ever need anything you can contact them, and they'll be there for you. (Mother, Service C)

Whilst the key worker relationship was clearly important to the women, data suggest that the sense of being cared for extended beyond the key worker relationship and was a consistent ethos across both services. Women described the kindness, approachability and helpfulness of the staff group.

I just look forward to coming through the door ... the building is just so calm and soothing ... you don't feel judged here. All the staff take their time with you and care. Like give you a room to sit in if need some space. Give you affection and care-I'm not used to that I never had that in childhood or ever since... They just think of all the small things and go out of the way for them. It's not just a job for them - they live to build women back up when they have been broken. (Mother, Service A)

I trust them - and after my experiences it is so hard to trust anyone. (Mother, Service A)

Developing trust through regularity, consistency and tenacity was important and yet also a careful balance not to be seen as another persecutory presence with some women finding the frequent visiting difficult.

They came around, like, twice, three times a week. And I used to say to them, like, "It's getting too much". Because it is. It ... I don't know. It just felt like somebody was there constantly, watching me. And, like, basically I said to them "It's ... it's getting too much". So, then, they came around once a week. And obviously they said if I needed anything in between then to give them a call." (Mother, Service C)

At first, it was really tense because everyone was around constantly and I wasn't left on my own and it wasn't ... it didn't feel so good but it's what had to be done, but ... they weren't coming just to pressure me and be all awful, they would come and make sure I had everything for [baby], and when I needed to go to the shop they'd go. And, like, just generally coming round to have a chat and make me feel a little bit at ease." (Mother, Service C)

Overall, these accounts indicate that flexibility of the service offer was central in sustaining engagement over time. 


\subsubsection{Building Confidence}

Women often described being isolated socially as a result of difficult family relationships, abusive partner relationships and a sense of social rejection from being deemed an unfit parent. The opportunity to be alongside women with shared experiences of child removal was important to mothers.

Being around other women who have been through similar experiences is really important, we are all in same boat-we are all at the same stage. We understand each other. I feel more calm about it because there are other women going through same and I'm not on my own. (Mother, Service A)

However, being able to join a group and share could be daunting and the services enabled women to gradually develop confidence in this.

It was really daunting at first, I struggle with groups and get severe anxiety, but they did it at my pace. I had 1:1 support first and then she just weaned me in (to the group) slowly. (Mother, Service A)

The facilitation of peer relationships enabled women to develop more social skills and confidence.

Coming to the group gets me out of the flat, gets me out communicating with other people and stuff and it's not letting me be on my own getting stuck in and isolating myself. It's getting me out, it's getting me out talking to other people and finding out what other people are up to and what they have been through and stuff. It's helped a lot. (Mother, Service A)

This social skills development also applied to support after birth where it seems that providing parenting skills training may have had the additional benefit of helping to develop social confidence because of the group format.

I think it was a baby one at first, like getting ready for the birth and stuff. I was scared of going out in case people judged me or anything and so I asked X and X if they could come. And they did for a few times, and then I started going on my own. (Mother, Service C)

Advice and support was perceived as comprehensive, non-judgemental and enabled mothers to develop more competence in a range of areas including those which may enable them to keep future children rather than assuming that they will not:

Literally everything. So, at the start when I was pregnant, like, what you need to do while you're pregnant, what meals you need to eat and what to avoid and, like, saying stuff about when the baby's born because when you're pregnant you're going to be confused so they're teaching you how to change a nappy, and feeding and just everything health, sleeping, safe sleeping and like that. Literally everything. (Mother, Service C)

\subsubsection{Taking Control of the Future}

The trusting and supportive relationship with key workers appeared key to enabling women to start feeling in control of their lives, set their own goals and targets for the future.

The situation I was in, I felt so out of control. They helped me to organise my thoughts. Helped me to see that I can take charge of all things in my life. They helped me to see what I needed to do, what I needed to prioritise and how I could take charge of my life. (Mother, Service A)

This self-esteem development appeared to be related to the nature of the key worker relationships described above:

$X$ praises me, so I think "you can do it, you've done it, be proud of yourself", stuff like that. It's nice to hear it off someone else, especially when you know you struggled the first time. (Mother, Service C) 
Many women in which the support they had allowed them to think of a more positive future. Women often hoped this future would include getting their children back but also included aspirations for employment, suggesting a degree of increased self-esteem.

I want my daughter back in my care and more kids and I want to be a qualified accountant. If you had asked me 12 months ago I would never have said that. (Mother, Service A)

Working with [Service C] it's helped gain my confidence. Like, helped me to bond with my child, because I never thought I would. Also, now I'm going to college, and I want eventually to do Health and Social Care. I've had a voluntary job in Barnardo's. (Mother, Service C)

Overall, our interviews with these women as users and also as co-producers of these new services offered insights into key elements of their recent and current experiences and future aspirations. Our findings here necessarily exclude those who opted not to be interviewed and who may have had different views on their service engagement.

\section{Discussion}

\section{'What Works' and 'What Matters'}

These evaluations have sought to identify 'what works' in local recurrent care services in order to enhance the development of national practice. They have assisted services to identify and understand interventions that help to avoid recurrent proceedings. However, they have also sought to identify 'what matters' to practitioners and service users. 'What works' and 'what matters' are clearly connected but it is also useful to consider them separately. Scholars writing in relation to criminal justice services have argued that the 'what works' framework prioritises the technical over other considerations [27,28]. It is also oriented towards the measurement and financialisation of 'hard outcomes' over 'soft outcomes', often driven by the short-term demands of service commissioners. Our mixed methods evaluations have aimed to create room for capturing 'what matters' to service users and practitioners while also providing some 'hard' outcome data to inform the negotiation of future commissioning. The three components of our evaluation toolkit aim to balance these different needs. Co-designed baseline surveys allow practitioners to exercise professional judgement to capture information in a case tracker that represents the complexity of each individual service user's social situation. Self-report measures allow service users to offer a personal assessment of elements of their own psychological situations. Qualitative interviews allow service users to reflect on their experiences of a given service.

In terms of 'what works', the combined evaluation data suggests that these three services have made significant contributions to the reduction of recurrent proceedings and associated cycles of temporary or permanent removals among groups of women who were otherwise likely to have experienced them. Yet this was not achieved only by prevention of pregnancy through LARC or other means, but also through enabling some mothers to keep new babies and facilitating the return of some children previously removed. This is significant because it suggests that women who have had children removed in the past can be supported to parent safely. Studies of 'early' family-based interventions linked to parent-infant mental health interventions and Family Drug and Alcohol Court (FDAC) programmes have similarly found that interdisciplinary work targeting individual needs can enable mothers previously deemed unable to parent, to develop anew their capacity to parent and to keep subsequent babies [7,29,30].

Our evaluation data suggests that professional support to parent safely can involve services engaging in a range of activities: encouraging women to desist from high risk behaviours (such as substance misuse); and/or supporting them to end or to manage high risk relationships (with, for example, violent partners); and/or supporting them to access their entitlements to benefits, housing and other social supports. Recurrent proceedings and associated removals can, therefore, be reduced by a range of factors that do not depend on the avoidance of pregnancy alone. Our data also offers new insight about the time windows in which support might be offered. A previous key study [1] 
has found that among women who have had previous children removed, the probability of further care proceedings within 2 years of a previous removal is $13.2 \%$, increasing to $22.4 \%$ within 5 years. The same study also shows that in a significant number of cases the proceedings 'overlapped' in that the mother was pregnant with a subsequent child before the initial proceedings concluded. In such instances, the mother was afforded very little time to be able to demonstrate any change in her previous risky behaviours or circumstances. A study drawing on these findings suggested that the optimum 'window' for intervention was within 18 months of the initial (or index) removal [6]. Data presented in the current article supports this in relation to Services A and B which saw low levels of removals over 12 months, but offers an alternative view in relation to Service $C$, which saw significant numbers of women able to keep their children over 5 years. This suggests that, in line with research on 'turning points' for mothers in a cycle of child removals [31], with appropriate and consistent support offered over several years, women deemed highly likely to experience recurrent proceedings can, in fact, develop parenting skills and other capacities, enabling them to keep a child in their care.

The outcomes of these three evaluations demonstrate that services of this kind offer their own intrinsic benefit to parents who seek to come to terms with the permanent removal of their child(ren), or who have a strong desire to have children who remain with them, or who wish to be good enough parents. However, the provision of such services carries a financial cost to the state via local authorities which means that their benefits must also be calculated in financial terms. Under current modes of governance, these costs then carry an embedded imperative to demonstrate the 'affordability' of state services. The state must, as a consequence, measure 'cost-effectiveness' as the ultimate 'hard' outcome. However, measuring cost effectiveness in this policy space is a complex process and requires calculations to be based on a range of assumptions that can only be approximations. It is possible to estimate cost savings from RCP services based on national statistics relating to the frequency and typical costs of care proceedings, as well as the typical long-term costs to the state of supporting 'looked after children'. These have been estimated as amounting to an average of $£ 32,263$ for each set of public law family court care proceedings and an average of $£ 52,676$ per year for children taken into care [32]. Pause evaluators have made estimations based on a combined average yearly cost of $£ 57,102$ including average costs of care and associated cost relating to proceedings [5]. In addition, RCP services are very likely to generate further substantial cost savings arising from the avoidance of exacerbation of parent mental health difficulties, drug and alcohol use and the future incidence of birth children becoming NEET (not in education, employment or training) category and/or experiencing their own mental health difficulties. On this basis, all three RCP services discussed here 'worked' in a concrete way in that they generated substantial financial savings to local authorities through avoided costs of removals along with the return of children who had been removed.

While these services may be generating net savings to state welfare budgets, they are also providing extremely valuable support to these women to meet their social needs, support their moves into work or education and support with difficult family issues or domestic situations. Yet our findings also indicate that high levels of psychological distress remain and clearly not all women benefit fully in all areas; indeed some continue to have children removed which can be a very traumatic experience. While some of the deterioration in psychological wellbeing along with increase in use of medication seen over time may be a result of more open reporting of problems, better self-reflective ability to recognise issues or increasing identification of issues through contact with health professionals, there may also be an inevitable worsening of symptoms as a result of unmet psychological need. This is consistent with a recent report of 1000 mothers whose babies were subject to care proceedings in Wales which found a high level of mental health problems among women whose children are removed at birth. Women in the sample were found to face particular challenges in accessing timely mental health support and were often given personality disorder diagnoses which adult mental health services were often reluctant to treat [33].

As would be the case for complex bereavement, it may be argued that this group of parents could benefit from targeted bereavement support to help manage the immediate effects of emotional 
strain from the initial child removal and its circumstances, followed by longer term psychological or other clinically-informed interventions to help address more ingrained psychological patterns arising from early trauma [34]. The clinical 'norm' for the measures used is a good indication of whether an adult experiencing the same level of distress would ordinarily be a person eligible for or already receiving specialist mental health intervention. It is important to consider why, given the level of distress being experienced by some of the women in these services, they have not been able to access more intensive therapeutic interventions delivered by psychological professionals. Given that these women have not accessed services matching their level of mental health need, they might be considered to be disadvantaged, with discrimination and stigma preventing them accessing NHS services they are equally entitled to. While resources for recurrent care services (developed by organisations such as Pause and Research in Practice) already include a range of training and information resources for developing trauma-informed practices for frontline workers, there is also a case for services expanding to include specialist trained mental health professionals to provide more intensive psychological interventions for those women who might benefit from it and who express significantly elevated levels of psychological distress.

\section{Conclusions}

This article draws on data gathered from three RCP services using a common evaluation framework. Using a mixed methods and realist evaluation approach, it contributes to the evidence-base about what works for, and what matters to, service users in these settings. It also has the potential to contribute to a wider community of practice in this field to inform further service development by sharing co-produced experiential learning. Local RCP services operating outside the national Pause model are small in scale but, as this article has argued, offer significant benefits to parents as well as a model of provision that is less reliant on the use of LARC and other forms of contraception to effect change, and more open to working with women who are (or become) pregnant at the point of engagement. If these benefits are to be scaled up and made more sustainable in the world of short-term service commissioning, such services need to be able learn from each other's successes and shortcomings.

Most significantly, we argue that the reduction of recurrent proceedings and associated removals does not depend on the avoidance of pregnancy alone. This is an important intervention, which challenges the current national service model's conditional requirements around contraception and thereby opens up new terrain for more varied types of service design, delivery, engagement and evaluation. That variation can encompass initiatives to encourage parents to desist from high risk behaviours, supporting them to end or to manage high risk relationships, and supporting them to access their entitlements to benefits, housing and other socio-economic supports.

The use of a common evaluation framework, such as the one outlined, here can help to advance that shared learning. The discussion of its design and use offered here contributes to debates around broader evaluation methodologies in this policy space. The framework has undoubted limitations. It cannot offer a singular assessment of the impact of a set of uniform interventions upon a group of uniform service users engaging over a uniform time period-not least because no RCP service operates in this way. It does, however, offer a robust, co-produced and flexible means of capturing outcomes from robust, co-produced and flexible services seeking to pioneer new ways to address a pressing policy issue.

Author Contributions: Conceptualization, P.C. and S.M.; methodology, P.C. and S.M.; formal analysis, S.M., V.B., C.M. and M.R.; investigation, S.M., V.B., C.M. and M.R.; data curation, S.M., V.B., C.M. and M.R.; writing-Original draft preparation, P.C. and S.M.; writing-Review and editing, V.B., C.M. and M.R.; project administration, V.B.; funding acquisition, P.C. and S.M. All authors have read and agreed to the published version of the manuscript.

Funding: Funding for the three evaluation projects was provided by the host organisations of the anonymous services evaluated, which were two UK County Councils (local government) and a UK third sector (charity) service provider.

Conflicts of Interest: The authors declare no conflict of interest. As detailed in the Methods section, the evaluation design and data collection were co-produced by the authors with front-line staff working in the services and 
employed by the funding organisation (i.e., the service providers). The funding organisations (service providers) had no role in the analyses, or interpretation of data; in the writing of the manuscript, or in the decision to publish the results. Funding was not contingent on the evaluation reporting positive results but on providing clear findings to inform service improvement and service development.

\section{References}

1. Broadhurst, K.; Alrouh, B.; Yeend, E.; Harwin, J.; Shaw, M.; Pilling, M.; Mason, C.; Kershaw, S. Connecting events in time to identify a hidden population: Birth mothers and their children in recurrent care proceedings in England. Br. J. Soc. Work 2015, 45, 2241-2260. [CrossRef]

2. Broadhurst, K.; Shaw, M.; Kershaw, S.; Harwin, J.; Alrouh, B.; Mason, C.; Pilling, M. Vulnerable birth mothers and repeat losses of infants to public care: Is targeted reproductive health care ethically defensible? J. Soc. Welf. Fam. Law 2015, 37, 84-98. [CrossRef]

3. Cox, P. Marginalized mothers, reproductive autonomy, and "repeat losses to care". J. Law Soc. 2012, 39, 541-561. [CrossRef]

4. Broadhurst, K.; Mason, C. Maternal outcasts: Raising the profile of women who are vulnerable to successive, compulsory removals of their children-A plea for preventative action. J. Soc. Welf. Fam. Law 2013, 35, 291-304. [CrossRef]

5. McChracken, K.; Priest, S.; FitzSimons, A.; Bracewell, K.; Torchia, K.; Parry, W.; Stanley, N. Evaluation Pause: Research Report. 2017. Available online: https://dera.ioe.ac.uk//29588/ (accessed on 12 November 2020).

6. Cox, P.; Barratt, C.; Blumenfeld, F.; Rahemtulla, Z.; Taggart, D.; Turton, J. Reducing recurrent care proceedings: Initial evidence from new interventions. J. Soc. Welf. Fam. Law 2017, 39, 332-349. [CrossRef]

7. McPherson, S.; Andrews, L.; Taggart, D.; Cox, P.; Pratt, R.; Smith, V.; Thandi, J. Evaluating integrative services in edge-of-care work. J. Soc. Welf. Fam. Law 2018, 40, 299-320. [CrossRef]

8. Soubhi, H.; Bayliss, E.A.; Fortin, M.; Hudon, C.; van den Akker, M.; Thivierge, R.; Posel, N.; Fleiszer, D. Learning and Caring in Communities of Practice: Using Relationships and Collective Learning to Improve Primary Care for Patients with Multimorbidity. Ann. Fam. Med. 2010, 8, 170-177. [CrossRef]

9. Wenger, E. Communities of Practice; Cambridge University Press: Cambridge, UK, 1998; ISBN 9780521430173.

10. Whiteford, M.; Byrne, P. Talking about alcohol: Communities of practice and patient pathways. J. Res. Nurs. 2015, 20, 12-25. [CrossRef]

11. Boddy, J.; Wheeler, B. Recognition and justice? Conceptualising support for women whose children are in care or adopted. Societies 2020, in press.

12. Burch, P.; Heinrich, C. Mixed Methods for Policy Research and Program Evaluation; Sage: Thousand Oaks, CA, USA, 2016; ISBN 9781452276625.

13. Pawson, R.; Tilley, N. What works in evaluation research? Br. J. Criminol. 1994, 34, 291-306. [CrossRef]

14. Pawson, R.; Tilley, N. Realistic Evaluation; Sage: London, UK, 1997; ISBN 9780761950097.

15. Broadhurst, K.; Mason, C. Child removal as the gateway to further adversity: Birth mother accounts of the immediate and enduring collateral consequences of child removal. Qual. Soc. Work 2020, 19, 15-37. [CrossRef]

16. Broadhurst, K.E.; Mason, C.S.; Webb, S. Birth Mothers Returning to Court: Can a Developmental Trauma Lens Inform Practice with Women at Risk of Repeat Removal of Infants and Children? In Justice for Children and Families; Shaw, M., Bailey, S., Eds.; Cambridge University Press: Cambridge, UK, 2018; pp. 59-67. ISBN 9781108457699.

17. Rosenberg, M. Society and the Adolescent Self-Image; Princeton University Press: Princeton, NJ, USA, 2015; ISBN 9781400876136.

18. Sim, J.; Machin, L.; Bartlam, B. Identifying vulnerability in grief: Psychometric properties of the Adult Attitude to Grief Scale. Qual. Life Res. 2014, 23, 1211-1220. [CrossRef] [PubMed]

19. Evans, C.; Connell, J.; Barkham, M.; Margison, F.; McGrath, G.; Mellor-Clark, J.; Audin, K. Towards a standardised brief outcome measure: Psychometric properties and utility of the CORE-OM. Br. J. Psychiatry 2002, 180, 51-60. [CrossRef] [PubMed]

20. Conybeare, D.; Behar, E.; Solomon, A.; Newman, M.G.; Borkovec, T.D. The PTSD Checklist-Civilian Version: Reliability, Validity, and Factor Structure in a Nonclinical Sample. J. Clin. Psychol. 2012, 68, 699-713. [CrossRef] [PubMed] 
21. Endicott, J.; Nee, J.; Harrison, W.; Blumenthal, R. Quality of Life Enjoyment and Satisfaction Questionnaire: A new measure. Psychopharmacol. Bull. 1993, 29, 321-326. [PubMed]

22. Jacobson, N.S.; Truax, P. Clinical Significance: A Statistical Approach to Defining Meaningful Change in Psychotherapy Research. J. Consult. Clin. Psychol. 1991, 59, 12-19. [CrossRef] [PubMed]

23. Braun, V.; Clarke, V. Using thematic analysis in psychology. Qual. Res. Psychol. 2006, 3, 77-101. [CrossRef]

24. Beck, J.G.; Tran, H.N.; Dodson, T.S.; Henschel, A.V.; Woodward, M.J.; Eddinger, J. Cognitive Trauma Therapy for Battered Women: Replication and extension. Psychol. Violence 2016, 6, 368-377. [CrossRef]

25. Twamely, E.W.; Allard, C.B.; Thorp, S.R.; Norman, S.B.; Hami Cissell, S.; Hughes Beradi, K.; Grimes, E.M.; Stein, M.B. Cognitive impairment and functioning in PTSD related to intimate partner violence. J. Int. Neuropsychol. Soc. 2009, 15, 879-887. [CrossRef]

26. Rapaport, M.H.; Endicott, J.; Clary, C.M. Posttraumatic Stress Disorder and Quality of Life. J. Clin. Psychiatry 2002, 63, 59-65. [CrossRef]

27. Mair, G. Introduction: What works and what matters. In What Matters in Probation; Mair, G., Ed.; Willan: Cullompton, UK, 2013; ISBN 9781843924920.

28. McNeill, F. What Works and What's Just? Eur. J. Probat. 2009, 1, 21-40. [CrossRef]

29. Harwin, J.; Ryan, M.; Broadhurst, K. How does FDAC Succeed with Parents with Substance Misuse Problems? Exploring Relational Practices within the English Family Drug and Alcohol Court. Child Abus. Rev. 2018, 27, 266-279. [CrossRef]

30. Harwin, J.; Broadhurst, K.; Cooper, C.; Taplin, S. Tensions and contradictions in family court innovation with high risk parents: The place of family drug treatment courts in contemporary family justice. Int. J. Drug Policy 2019, 68, 101-108. [CrossRef] [PubMed]

31. Broadhurst, K.; Mason, C. Recurrent care proceedings: Part 3: Birth mothers-Against the odds: Turning points for women who have lost children to public care. Fam. Law 2014, 44, 1572-1576.

32. Department for Communities and Local Government Troubled Families Cost Database. 2015. Available online: https://www.greatermanchester-ca.gov.uk/what-we-do/research/research-cost-benefit-analysis/ (accessed on 12 November 2020).

33. Griffiths, L.; Johnson, R.; Broadhurst, K.; Cusworth, L.; Bedston, S.; Jones, K.; Akbari, A.; Lee, A.; Alrouth, B.; Doebler, S.; et al. Born into Care: One Thousand Mothers in Care Proceedings in Wales: Maternal Health, Wellbeing and Pregnancy Outcomes; Nuffield Family Justice Observatory: London, UK, 2020.

34. Sweeney, A.; Taggart, D. (Mis)understanding trauma-informed approaches in mental health. J. Ment. Health 2018, 27, 383-387. [CrossRef] [PubMed]

Publisher's Note: MDPI stays neutral with regard to jurisdictional claims in published maps and institutional affiliations.

(C) 2020 by the authors. Licensee MDPI, Basel, Switzerland. This article is an open access article distributed under the terms and conditions of the Creative Commons Attribution (CC BY) license (http://creativecommons.org/licenses/by/4.0/). 